\section{4-5.2 TEACHING ABOUT CHRONIC DISEASES IN MEXICO THROUGH THE LATIN AMERICAN SUPERCOURSE}

doi:10.1136/jech.2011.142976b.31

${ }^{1} \mathrm{~N}$ Padilla, ${ }^{*} \mathrm{~F}$ Linkov, ${ }^{3} \mathrm{E}$ Shubnikov, ${ }^{2} \mathrm{R}$ LaPorte. ${ }^{1}$ Campus Celaya Salvatierra University of Guanajuato, Spain; ${ }^{2}$ University of Pittsburgh, Pittsburgh, Pennsylvania, USA; ${ }^{3}$ nstitute of Internal Medicine, Russia, Russian Federation

The Global Health Network Supercourse project was launched in late 1990's with the main objective to empower public health teachers around the world by providing to them with up to date scientific PowerPoint lectures. Parent Supercourse has over 50000 faculty members from 174 countries and a library of over 4700 lectures. In order to reach out to faculty members in Spanish speaking countries, Latin American Supercourse has been launched, featuring parent Supercourse lectures and their Spanish translations.

Google analytics ${ }^{\circledR}$ has been used to evaluate the number of hits for the parent Supercourse vs Latin American Supercourse. Basic statistics have been used to compare the scores between parent Supercourse and Latin American Supercourse. Using Google analytics ${ }^{\circledR}$, from 10 June 2009 to 10 June 2010, it has been discovered that parent Supercourse had 257403 unique visits at the home website. The lectures in English were the most popular, followed by Spanish lectures.

Latin American Supercourse was launched over 3 years ago, with more than 500 lectures translated into Spanish and 30000 access to the main webpage. Latin American Supercourse has over 1000 active members that receive newsletters and updates on monthly basis.

Success of the Latin American Supercourse is very encouraging. It demonstrates that Spanish language lectures are needed and widely used. Further development and evaluation of the Latin American Supercourse project will be the next step of this important endeavour.

\section{4-5.3 EPIDEMIOLOGY AND THE PREVENTION OF CANCER BY TACKLING THE OBESITY EPIDEMIC: TRADITIONAL AND NOVEL APPROACHES}

doi:10.1136/jech.2011.142976b.32

${ }^{1} \mathrm{~F}$ Linkov, ${ }^{*}{ }^{2} E$ Shubnikov, ${ }^{1} \mathrm{R}$ LaPorte, ${ }^{1} \mathrm{R}$ Ramanathan, ${ }^{1} \mathrm{G}$ Hamad, ${ }^{1} \mathrm{~A}$ Courcoulas, ${ }^{1} \mathrm{D} \mathrm{H}$ Bovbjerg. ${ }^{1}$ University of Pittsburgh, Pittsburgh, Pennsylvania, USA; ${ }^{2}$ Institute of Internal Medicine, Novosibirks, Russian Federation

Cancer is becoming the number one cause of death around the world. While significant advanced have been made in the management of several cancers, prevention is still the best way to relieve the burden of this deadly disease. Obesity epidemic observed in both developing and developed world may potentially fuel cancer epidemic. Obesity is a major risk factor for the development of endometrial cancer. An improved understanding of biologic mechanisms associated with weight loss may guide preventive strategies for endometrial cancer development. At the University of Pittsburgh Cancer Institute, we are coordinating several studies where we are investigating the link between intentional weight and changes in biomarkers associated with cancer. In addition to traditional weight management approaches such as diet, exercise, and bariatric surgery, we believe that we need to start exploring the utility of mobile devices to spread the world about cancer prevention through effective weight management. Over the last decade, the number of mobile phone users worldwide increased dramatically, with over $80 \%$ of the world's population having access to mobile phones in 2011. Mobile apps are increasingly popular especially in the area of health and exercise, especially among smart phone users. While several "anti-obesity" apps became available in the past year to fight obesity epidemic among kids, we did not yet accumulate enough research information to evaluate their effectiveness. We are trying to build a dialogue between the experts in epidemiology, obesity, and mobile technology for the prevention of obesity and chronic conditions associated with obesity.

\section{4-5.4 MOBILE GLOBAL HEALTH SUPERCOURSE IN THE FSU}

doi:10.1136/jech.2011.142976b.33

${ }^{1} \mathrm{E}$ Shubnikov, ${ }^{*} \mathrm{~K}$ Daburov, ${ }^{3} \mathrm{~A}$ Troufanov, ${ }^{4} \mathrm{~F}$ Linkov, ${ }^{4} \mathrm{R}$ LaPorte. ${ }^{1}$ Institute of Internal Medicine, Novosibirsk, Russian Federation; ${ }^{2}$ Abuali Sino State Medical University, Tajikistan, Tajikistan; ${ }^{3}$ rrkutsk State Technical University, Irkutsk, Russian Federation; ${ }^{4}$ University of Pittsburgh, Pittsburgh, Pennsylvania, USA

Former Soviet Union (FSU) Supercourse was created in the framework of the Supercourse project-http://www.pitt.edu/ super1. As of 2011, 15 FSU countries are heterogeneous in socioeconomic status, but still have very similar systems of public health, clinical medicine, and information technologies. Most of countries are not demonstrating a rapid increase in life expectancy and need improvements in health status. Education and information sharing is important to preventing all forms of diseases and conditions. Mobile Technology provides a powerful and inexpensive tool for the improvement of health through prevention. There are 1.94 cell phones for every one person living in Estonia, 1.43 in Lithuania and 1.33 in Russia. To date, more than 500 public health workers from all 15 FSU countries have participated to integrate Internet-based education for the prevention of all forms of diseases. The FSU Supercourse is collaboration of FSU scientists involved in prevention and the Internet for development of Russian language library of lectures. The Russian language Supercourse currently has more than 250 Russian language lectures. Our FSU Supercourse is a backbone for Mobile global health Project in FSU countries. Our mission is to double training in global health and prevention in the next 2 years. We want to marry our work with those interested in Mobile Technology to build a new discipline called FSU Mobile Global health. Our goal is the development of FSU MobileGlobal Health network, where we can improve health using Mobile Technology. 